\title{
Doped bentonitic grouts for implementing performances of low-enthalpy geothermal systems
}

Marco Viccaro ${ }^{1,2^{*}}$ (1)

\footnotetext{
${ }^{*}$ Correspondence:

m.viccaro@unict.it

1 Dipartimento di Scienze

Biologiche Geologiche e

Ambientali - Sezione di

Scienze della Terra, Università degli Studi di Catania, Corso Italia 57, 95129 Catania, Italy Full list of author information is available at the end of the article
}

\begin{abstract}
Mechanical (flexural and uniaxial compressive strengths) and physical (thermal conductivity) properties of two new bentonitic grouts doped with 5 and 10\% of graphite powder are discussed in this work and evaluated for their potential use in low-enthalpy geothermal applications. The same tests have been also conducted on a pure starting material (bentonitic grout) already present on the market and used to seal geothermal probes into boreholes. Experimental data show that the addition of 5 and $10 \%$ of graphite powder positively alters the mechanical properties of the doped bentonitic grouts, i.e., both flexural and uniaxial compressive strengths increased with respect to those of the pure material. Thermal conductivity also improved up to $60 \%$ in the doped bentonitic grouts. A simple analysis of the cost/benefit ratio suggests, however, that the bentonitic grouts doped with $5 \%$ of graphite powder is more suitable and competitive for a launch on the market and utilization as a sealing material in boreholes aimed at low-enthalpy geothermal installations. Implementation of thermal properties of the grout material implicates a reduction of the total borehole length of $15-20 \%$.
\end{abstract}

Keywords: Low-enthalpy geothermal energy, Flexural strength, Uniaxial compressive strength, Thermal conductivity, Borehole, Bentonitic grout, Graphite powder

\section{Background}

Energy is a fundamental condition for the social growth of the community, being an essential ingredient for almost all human activities and services. During the past decade, the energy policy has been working towards more environmental-friendly renewable power plants in order to achieve maximum advantages and/or fewer impacts from the exploitation of fossil-fuel resources (Kalaiselvam and Parameshwaran 2014). Efforts have been concentrated mainly in the field of applied solar and wind energy (generally promoted by many subventions), and geothermal energy played comparatively a less prominent role among renewable sources. Although anomalous geothermal fluxes useful for exploitation are present in specific geological settings, there is a worldwide incredible potential related to low-enthalpy geothermal energy that is, at present, scarcely considered in many countries (Banks 2012 and references therein). In this regard, primary reasons are the lack of scientific-technical background in the field of low-enthalpy geothermal resources, coupled with the absence of adequate basic information of 
small-to-medium scale subsoil characteristics that are essential to appropriately manage feasibility studies.

It is worth to note that the majority of low-enthalpy geothermal systems have negligible environmental impact, chiefly because energy capture systems are placed into the ground and they can be fully integrated into the subsurface if planned during the construction phase of buildings (cf. also Florides and Kalogirou 2007). Low-enthalpy geothermal systems can, therefore, become of strategic importance in the near future, especially if technological efforts will point towards an improvement of their cost/benefit ratio in comparison with other renewable energy systems (Kalaiselvam and Parameshwaran 2014 and references therein). Indeed, the ability to produce energy for heating in winter, cooling in summer and heating water makes low-enthalpy geothermal energy the ideal alternative to other traditional systems. The advantage is given by the fact that a single installation includes functions normally delegated to different devices (e.g., boilers, air conditioners, etc.). Also, heating and cooling systems from low-enthalpy geothermal energy seem to be the most acceptable solution in circumstances where solar thermal or photovoltaic are prevented (e.g., scarce exposure to solar radiation, intense urbanization, protected natural/archeological sites, historical city centers, etc.).

Low-enthalpy geothermal systems are based on a rather simple technology of heat exchange with the subsoil (e.g., Florides and Kalogirou 2007). Beside the chemical-physical characteristics of rocks in the subsurface (which anyhow remain a paramount factor), the total efficiency of the installation is determined by the following: (1) efficiency of the Ground Source Heat Pump, which allows the transfer of heat from the subsoil upward to the surface; (2) efficiency of thermal exchange between probes installed in boreholes and rocks in the subsurface; (3) chemical-physical characteristics of the bentonitic grout to seal probes into boreholes; (4) efficiency of the heat distribution system into the environment at the surface. During the past years, technological development has been pointing with increasing interest towards new materials and solutions able to enhance the performances of one or more of these components, with particular reference to the composition of the grout used as sealing material in the boreholes (e.g., Smith and Perry 1999; Alrtimi et al. 2009; Wang et al. 2011; Delaleux et al. 2012; Desmedt et al. 2012; Lee et al. 2012; Borinaga-Treviño et al. 2013; Kim et al. 2013; Erol and Francois 2014; Indacoechea-Vega et al. 2015; Blazquez et al. 2017). Some innovative solutions have also found applications in other related fields of interest of bentonitic grouts, such as thermal storage (e.g., Sari 2016) or sealing of radioactive wastes (Tang et al. 2008; Jobmann and Buntebarth 2009).

Sealing the boreholes with mixtures of bentonitic grout should guarantee either perfect hydraulic insulation (e.g., among aquifers intercepted during the perforation) or good heat exchange between the geothermal probes and the subsoil. The permeability, generally on the order of $10^{-10} \mathrm{~cm} / \mathrm{s}$, and the flow ability of the sealing material during the fresh state of the grout are also important for the hydraulic sealing of the aquifers and for good performances during pumping into the borehole. In this regard, Fleuchaus and Blum (2017) put into evidence that the connection of aquifers by leaky annular space grouting can be the cause of damages to the installation. The use of bentonitic cements, more than pure cements, also ensures elasticity of the sealing structure, avoiding damages due to contractions ascribable to anthropic and natural solicitations. This 
becomes a crucial factor especially for low-enthalpy geothermal installations placed in areas affected by recurrent freeze-thaw cycles that cause circumferential effective stresses (Anbergen et al. 2014; Erol and Francois 2015). Furthermore, the use of bentonitic cements is beneficial also for installation in intensely urbanized areas (e.g., vibrations due to heavy traffic, subway, etc.) or in geologically and tectonically areas with high vulnerability, which can be frequently subjected to elevated risks (seismic, hydrogeological, etc.) producing continuous mechanical stress on the technological system. Pure bentonite, however, has very poor thermal conductivity $[\ll 1 \mathrm{~W} / \mathrm{m} \mathrm{K}$; e.g., Tang et al. (2008); Jobmann and Buntebarth (2009); Kim et al. (2015); Sari (2016)]. This means that its massive utilization in the mixture produces significant reduction of the thermal conductivity and, therefore, of the thermal exchange into the borehole between probes and subsoil. In this regard, some authors have already investigated the possibility to improve the thermal exchange by enhancing the thermal conductivity of the sealing grout in the boreholes by adding components (e.g., quartz, sands, carbon-based components, etc.) at high thermal conductivity in the mixture (Delaleux et al. 2012; Lee et al. 2012; Erol and Francois 2014; Indacoechea-Vega et al. 2015). In these instances, however, the mechanical properties of the obtained grouts were not verified or the experimentally determined thermal conductivity is too high $(>6 \mathrm{~W} / \mathrm{m} \mathrm{K})$ and far from common values observable on Earth (average thermal conductivity of rocks in the subsurface is $3.2 \mathrm{~W} / \mathrm{m} \mathrm{K}$; Eppelbaum et al. 2014 and references therein). However, experimentation and production of new materials should always ensure exceptional resistance and flexibility of the grout in the borehole, together with thermal conductivity capable to assure balanced thermal exchange with the subsoil. Indeed, thermal conductivity needs to be maintained at values compatible with those of the surrounding subsurface in order to reduce the occurrence of thermal short-circuits in the borehole with the consequent loss of performance of the whole low-enthalpy geothermal system. This is even more valid for areas characterized by subsoils with very low thermal conductivity (e.g., $0.3-2.3 \mathrm{~W} / \mathrm{m} \mathrm{K}$ for clays, silt, water saturated and dry sands; Eppelbaum et al. 2014 and references therein), which can become the main resistance of the whole exchange system. All these aspects lead to the final consideration that a compromise needs to be found to obtain commercial products characterized by good mechanical and physical properties.

This work presents results coming from the experimental production of two original bentonitic grouts bearing an additive with high thermal conductivity (pure graphite powder). With respect to previous literature, this study is aimed at finding an optimum grout mixture with enhanced properties from both mechanical and thermal standpoints. Improvement of mechanical properties (flexural and uniaxial compressive strengths) together with increase of thermal conductivity makes these two mixtures highly suitable for their use as effective sealing grout into boreholes for geothermal probe installations, having also the advantage of implementing the thermal exchange between the technological system and the subsoil.

\section{Methods}

A bentonitic grout already launched in the market has been used as starting material. The grout mixture is composed of fine-grained $(<0.1 \mathrm{~mm})$ cement with addition of $4 \%$ of bentonite. Declared density of the fresh starting grout for pumping ranges between 
$1.49 \mathrm{~kg} / \mathrm{dm}^{3}$ and $1.65 \mathrm{~kg} / \mathrm{dm}^{3}$, depending on the water/solid ratio used to prepare the mixture. Declared fluidity for $1000 \mathrm{ml}$ of suspension is $45 \mathrm{~s}$ (Marsh Cone Test with nozzle of $10 \mathrm{~mm}$ following the UNI 11,152:2005 normative for draining). For the investigated purposes, technical specifications declared for this bentonitic mixture report flexural strength $\sim 2 \mathrm{~N} / \mathrm{mm}^{2}$ and uniaxial compressive strength $\sim 3 \mathrm{~N} / \mathrm{mm}^{2}$ after 28 days (following the DIN 18136:2003-2011 normative) and thermal conductivity $\geq 1 \mathrm{~W} / \mathrm{mK}$. The additive used for the experimental production of the new bentonitic grouts is pure graphite powder, with grain size analogous to that of the starting material (i.e., grain size $\leq 0.50 \mu \mathrm{m}$ ) and thermal conductivity $>50 \mathrm{~W} / \mathrm{mK}$ (cf. Clauser and Huenges 1995). Mechanical and physical properties have been determined on three typologies of samples: (1) starting material; (2) starting material plus 5\% of graphite powder; (3) starting material plus $10 \%$ of graphite powder. The starting material has been also included in mechanical and physical tests, just to minimize the possible analytical bias and to evaluate true differences among the three mixtures. All samples have been prepared at the accredited laboratories of SIDERCEM srl (Misterbianco, Sicily) by using a colloidal grout mixer. Mixtures have been prepared following the UNI EN 196-1:2016 normative in $160 \times 40 \times 40$ prismatic molds with proportions reported in Table 1. Drying of samples has been performed at temperature of $+20{ }^{\circ} \mathrm{C}$ and humidity ranging between 95 and $99 \%$ into rooms able to monitor continuously the environmental parameters.

Flexural and uniaxial compressive strengths have been determined by a TECNOTEST KE 72 instrument equipped with 4 reading channels and a digital dynamometer able to perform tests for compression, flexure, indirect tensile, paving blocks, breaking in load/ deformation control, elastic module up to 999 cycles of loading/unloading for evaluations of creeping or ductility of various building materials. Measurements of flexural strength have been performed on 1 sample of pure material after 14 days and 2 samples after 28 days. The same number of samples has been investigated for the starting material doped with 5 and $10 \%$ of graphite powder after 14 and 28 days. Measurements of uniaxial compressive strength have been performed on 2 samples of pure material after 14 days and 4 samples after 28 days. The same number of samples has been investigated for the starting material doped with 5 and $10 \%$ of graphite powder.

Experimental determinations of thermal conductivity have been conducted on 4 different samples of starting material and 10 different samples of the doped bentonitic grouts ( 5 samples for each mixture with 5 and 10\% of graphite powder). Measurements have been performed through a heat flow meter Shotherm QTM Showa Denko at the laboratories of Technical Physics of the DIEEI of the University of Catania following the UNI EN 12664:2002. This instrument uses the non-stationary hot-wire method at

Table 1 Components used for the preparation of the bentonitic grout mixtures with various proportions of pure graphite powder as additive (G0\% no graphite powder; G5\% mixture with $5 \%$ of graphite; G10\% mixture with $10 \%$ of graphite)

\begin{tabular}{lccl}
\hline Component/weight $(\mathbf{g})$ & Mixture G0\% & Mixture G5\% & Mixture G10\% \\
\hline Starting material & 1000 & 950 & 900 \\
Pure graphite powder & 0 & 50 & 100 \\
Water & 600 & 600 & 600
\end{tabular}

Data refer to weights of components reported in grams 
constant heat flow and operates in the temperature range from -10 to $+200{ }^{\circ} \mathrm{C}$ with precision and reproducibility in the order of $2 \%$. The procedure allows the heat transfer from the instrument to the sample with consequent temperature increase (fixed at maximum $20^{\circ} \mathrm{C}$ ) through generation of coaxial cylindrical isotherms. Heating time is $45 \mathrm{~min}$, whereas measurement duration is $180 \mathrm{~s}$. This method ensures no significant changes of the material properties during measurements, as demonstrated in other studies performed on similar materials (Fukai et al. 2000; Karaipekli et al. 2007; Lee et al. 2010).

\section{Results}

\section{Mechanical properties}

Flexural and compressive strengths of the starting bentonitic grout and of grouts with the graphite powder additive at 5 and $10 \%$ after 14 and 28 days have been reported in Tables 2 and 3. Flexural strength $\left(R_{\mathrm{f}}\right)$ has been determined from the relation:

$$
R_{\mathrm{f}}=\left(1.5 F_{\mathrm{f}} / b^{3}\right) \times l
$$

where $F_{\mathrm{f}}$ is the strength applied at the center of the prismatic sample, $b^{3}$ is the side dimension of the resistant section, $l$ is the distance between the two supports.

Compressive strength has been determined as follows:

$$
R_{\mathrm{c}}=F_{\mathrm{c}} / a b,
$$

where $F_{\mathrm{c}}$ is the breaking load, $a$ and $b$ the sides of the resistant section.

Each typology of material displays an increase of both flexural and uniaxial compressive strengths with time, i.e. with measurements performed at 14 and 28 days (Tables 2, $3)$. Tests performed on the starting material confirm values of the flexural and uniaxial compressive strengths after 28 days declared in the technical specification of the product, being, respectively, $1.99 \mathrm{~N} / \mathrm{mm}^{2}$ (average on 2 samples) and $3.33 \mathrm{~N} / \mathrm{mm}^{2}$ (average on 4 samples). Both the bentonitic grouts with 5 and $10 \%$ of graphite powder additive

Table 2 Flexural strengths $\left(R_{f}\right)$ at the fracture point obtained on the starting and doped

\begin{tabular}{|c|c|c|}
\hline & $F_{\mathrm{f}}(\mathrm{N})$ & $R_{\mathrm{f}}\left(\mathrm{N} / \mathrm{mm}^{2}\right)$ \\
\hline \multicolumn{3}{|l|}{ Pure starting material } \\
\hline June 30, 2016 (14 days) & 490 & 1.84 \\
\hline July 14, 2016 (28 days) & 500 & 1.88 \\
\hline July 14, 2016 (28 days) & 560 & 2.10 \\
\hline \multicolumn{3}{|l|}{ Starting material + 5\% } \\
\hline June 30, 2016 (14 days) & 930 & 3.49 \\
\hline July 14, 2016 (28 days) & 980 & 3.68 \\
\hline July 14, 2016 (28 days) & 1080 & 4.05 \\
\hline \multicolumn{3}{|l|}{ Starting material + 10\% } \\
\hline June 30, 2016 (14 days) & 820 & 3.08 \\
\hline July 14, 2016 (28 days) & 1060 & 3.98 \\
\hline July 14, 2016 (28 days) & 1000 & 3.75 \\
\hline
\end{tabular}
(+ 5 and $+10 \%$ of graphite powder) bentonitic grouts

$F_{\mathrm{f}}$ indicates the load applied at the center of the sample at the fracture point. Dates indicate times between preparation and realization of the mechanical tests (at 14 and 28 days) 
Table 3 Uniaxial compressive strengths $\left(R_{c}\right)$ at the fracture point obtained on the starting and doped ( +5 and $+10 \%$ of graphite powder) bentonitic grouts

\begin{tabular}{|c|c|c|}
\hline & $F_{\mathrm{c}}(\mathrm{N})$ & $R_{\mathrm{c}}\left(\mathrm{N} / \mathrm{mm}^{2}\right)$ \\
\hline \multicolumn{3}{|l|}{ Starting material } \\
\hline June 30, 2016 (14 days) & 4370 & 2.73 \\
\hline June 30, 2016 (14 days) & 4680 & 2.93 \\
\hline July 14, 2016 (28 days) & 4850 & 3.03 \\
\hline July 14, 2016 (28 days) & 4870 & 3.04 \\
\hline July 14, 2016 (28 days) & 5860 & 3.66 \\
\hline July 14, 2016 (28 days) & 5740 & 3.59 \\
\hline \multicolumn{3}{|c|}{ Starting material + graphite 5\% } \\
\hline June 30, 2016 (14 days) & 9020 & 5.64 \\
\hline June 30, 2016 (14 days) & 8830 & 5.52 \\
\hline July 14, 2016 (28 days) & 9830 & 6.14 \\
\hline July 14, 2016 (28 days) & 9620 & 6.01 \\
\hline July 14, 2016 (28 days) & 10,150 & 6.34 \\
\hline July 14, 2016 (28 days) & 10,230 & 6.39 \\
\hline \multicolumn{3}{|c|}{ Starting material + graphite 10\% } \\
\hline June 30, 2016 (14 days) & 8150 & 5.09 \\
\hline June 30, 2016 (14 days) & 8910 & 5.57 \\
\hline July 14, 2016 (28 days) & 11,520 & 7.2 \\
\hline July 14, 2016 (28 days) & 11,320 & 7.08 \\
\hline July 14, 2016 (28 days) & 10,630 & 6.64 \\
\hline July 14, 2016 (28 days) & 10,750 & 6.72 \\
\hline
\end{tabular}

$F_{c}$ indicates the load applied at the fracture point. Dates indicate times between preparation and realization of the mechanical tests (at 14 and 28 days)

display increase of the flexural and uniaxial compressive strengths with respect to the starting material, either after 14 days from the production or after 28 days (Tables 2, 3). On the whole, measurements put into evidence comparable flexural strengths for samples with the graphite powder additive at 5 and $10 \%$ after 28 days (average $3.87 \mathrm{~N} / \mathrm{mm}^{2}$ for both; Table 2), whereas slight differences have been observed for what concerns the obtained uniaxial compressive strengths and their evolution during the drying process (Table 3). Specifically, the bentonitic grout with $5 \%$ graphite powder additive shows, on average, uniaxial compressive strength at $5.58 \mathrm{~N} / \mathrm{mm}^{2}$ after 14 days and increase at $6.22 \mathrm{~N} / \mathrm{mm}^{2}$ after 28 days. The bentonitic grout with $10 \%$ graphite powder additive exhibits, on average, lower values of uniaxial compressive strength after 14 days (5.33 N/ $\mathrm{mm}^{2}$ ) with respect to the bentonitic grout with $5 \%$ of graphite powder additive, but values are the highest after 28 days $\left(6.91 \mathrm{~N} / \mathrm{mm}^{2}\right)$.

\section{Thermal conductivity}

Thermal conductivity of the starting bentonitic grout and mixtures with the graphite powder additive at 5 and $10 \%$ on samples after 28 days has been reported in Table 4 . The experimental values of thermal conductivity $(\lambda)$ have been calculated as a function of the temperature-time curve $(T-\tau)$ and the heat flow at the input $(q)$ through the following equation:

$$
\lambda=\left[q \times \ln \left(\tau_{2} / \tau_{1}\right)\right] /\left[4 \pi\left(T_{2}-T_{1}\right)\right]
$$


Table 4 Thermal conductivity obtained on the starting and doped $(+5$ and $+10 \%$ of graphite powder) bentonitic grouts

$\lambda(\mathrm{W} / \mathrm{m} \mathrm{K})$

\begin{tabular}{lc}
\hline Starting material & \\
1st measurement & 1198 \\
2nd measurement & 1207 \\
3rd measurement & 1171 \\
4th measurement & 1186 \\
Starting material + graphite 5\% & \\
1st measurement & 1861 \\
2nd measurement & 1819 \\
3rd measurement & 1940 \\
4th measurement & 1872 \\
5th measurement & 1896 \\
Starting material + graphite 10\% & \\
1st measurement & 1917 \\
2nd measurement & 1963 \\
3rd measurement & 2013 \\
4th measurement & 1928 \\
5th measurement & 2045 \\
\hline
\end{tabular}

Equation (3) can be implemented according to electrical current and voltage following the relation:

$$
\lambda=K \times\left[I^{2} \times \ln \left(\tau_{2} / \tau_{1}\right)\right] /\left[4 \pi\left(V_{2}-V_{1}\right)\right]-H,
$$

where $K$ and $H$ are constants for the instrument calibration, $I$ the electrical current and $\left(V_{2}-V_{1}\right)$ the electric potential.

Measurements performed on the starting material confirm thermal conductivity as declared in the technical specifications, being the obtained $\lambda=1.191 \mathrm{~W} / \mathrm{m} \mathrm{K}$ (Table 4; average of 4 repeated measurements). Bentonitic grouts doped with graphite powder at 5 and $10 \%$ present increase of the thermal conductivity up to ca. $60 \%$. Specifically, the average thermal conductivity of the bentonitic grout at $5 \%$ is $1.878 \mathrm{~W} / \mathrm{m} \mathrm{K}$ and further increases at $1.973 \mathrm{~W} / \mathrm{m} \mathrm{K}$ for the mixture with $10 \%$ of graphite powder (Table 4; average of 5 repeated measurements for both).

\section{Discussion}

\section{Optimum doping rate defined by mechanical vs. thermal properties}

The experimental results on bentonitic grouts presented in this work have been only evaluated for mechanical and physical properties useful for geothermal applications, which means that experimental materials have not any claim in order to be used as structural concretes for construction and/or building materials. Results emphasize the importance of graphite powder as additive in bentonitic grouts. Indeed, graphite powder is basically inert, so it does not alter the drying/compaction process of the bentonitic grout. Furthermore, small addition (5-10\%) of graphite powder improves the flexural and uniaxial compressive strengths of the bentonitic grout after 14-28 days (times commonly assumed for structural concretes), having also the advantage of increasing its final thermal conductivity up to $60 \%$. Improvement of the investigated mechanical properties 
suggests that the experimental bentonitic grouts doped with graphite powder can be even more resistant to various possible damages after the installation (e.g., freeze-thaw cycles, natural vs. anthropic vibrations, etc.). At identical water/solid ratios, density of the fresh doped grout $\left(\sim 1.7 \mathrm{~kg} / \mathrm{dm}^{3}\right.$ for the mixture at $5 \%$ and $\sim 1.8 \mathrm{~kg} / \mathrm{dm}^{3}$ for the mixture at $10 \%$ ) is not significantly modified with respect to that of the fresh starting material $\left(\sim 1.5 \mathrm{~kg} / \mathrm{dm}^{3}\right)$. Fluidity has been evaluated through the Marsh Cone Test (UNI EN 445:2007, nozzle of $10 \mathrm{~mm}$ ) following indications of the UNI 11152:2005 normative during the draining process. Declared fluidity for $1000 \mathrm{ml}$ of the fresh starting material for pumping is $45 \mathrm{~s}$, whereas measured fluidities of the fresh doped grouts are 65 and $85 \mathrm{~s}$ for the mixture at 5 and $10 \%$ of graphite powder, respectively. These values are well in the range (45-100 s) of other optimized bentonitic grouts generally found on the market, which therefore ensure good performances during the pumping process of the grout into the borehole.

It is worth noting that the amount of graphite powder added to the bentonitic grout affects the final cost of the experimental product. As a consequence, choice of a mixture with minimal quantities of additive is certainly fundamental to guarantee a competitive commercial strategy, even maintaining improvement of the mechanical and physical properties of the final product. Looking at the flexural and uniaxial compressive strengths of the starting material and those of the experimental bentonitic grouts with 5 and $10 \%$ of graphite powder, a significant difference between the starting material and both the doped bentonitic grouts can be observed (Fig. 1). However, the experimental mixtures doped at 5 and $10 \%$ by graphite powder display final values that, although slightly different, appear rather clustered within the same order of magnitude (Fig. 1). Similar trends are also recognizable for thermal conductivity (Fig. 2). Reasons to explain comparable values for the grouts doped at 5 and $10 \%$ are not clear. Addition of graphite can bring to two antagonistic effects: (1) graphite particles have high thermal conductivity, which finally increases that of the bentonite-graphite mixture and (2) at the same time, graphite addition could increase the porosity of the whole mixture, having opposite effect on the overall thermal conductivity. These two effects are, therefore, in competition: for a doping rate of $5 \%$ the first probably prevails, whilst the second starts to become important for the mixture at doping rate of $10 \%$. This suggests that the mechanical vs. thermal optimum is at the doping rate of $5 \%$ of graphite.

Definition of the cost/benefit ratio is also paramount for the ultimate launch in the market of a competitive experimental product. Simple commercial considerations lead to the idea that utilization of bentonitic grouts doped at $10 \%$ with graphite powder probably does not satisfy the cost/benefit ratio. Following evaluations have been, therefore, conducted considering only the bentonitic mixture with $5 \%$ of graphite powder as additive. Pure graphite powder has rather elevated commercial cost, estimable in $0.0035 € /$ gm throughout the European market at the retail level. However, industrial supply of graphite powder may reasonably undergo to favorable discount up to $30-40 \%$ depending on the requested amounts. The additional cost due to the graphite powder additive can be, therefore, estimable in ca. 1000-1200 € per ton of bentonitic grout. Principal benefits resulting from the improved thermal conductivity of the bentonitic mixture are consequent in sizing of the total thermal exchange surface between the geothermal probes and the subsoil, which is quantifiable taking into account the probe cross-section (diameter) 

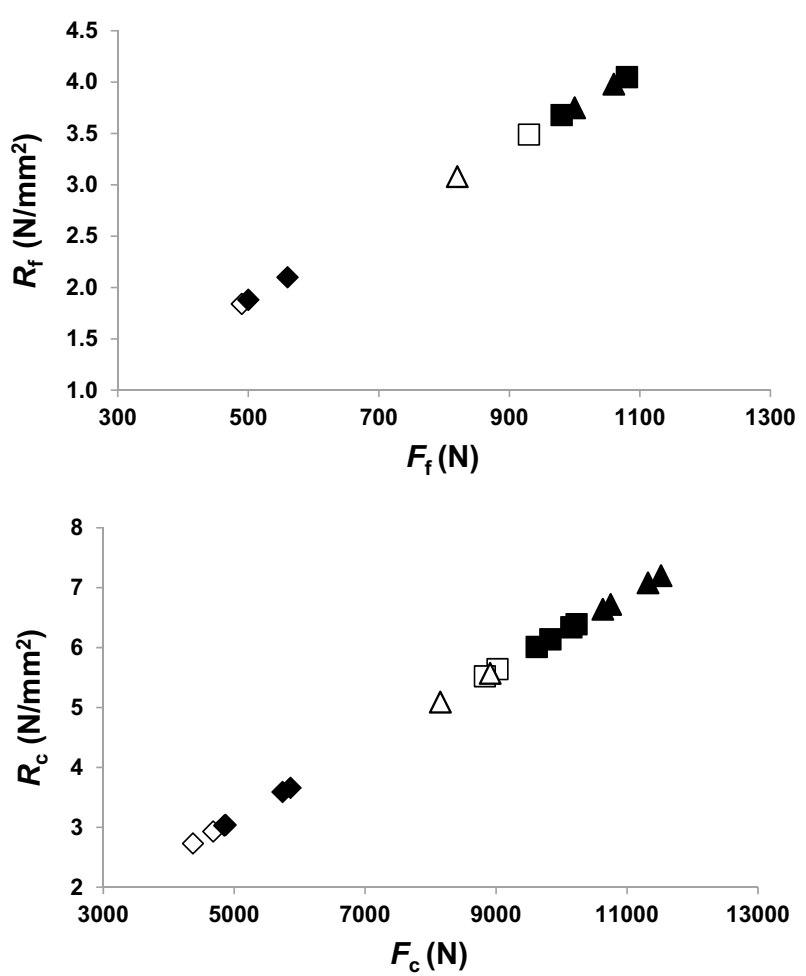

Fig. 1 Diagram reporting the flexural $\left(R_{f}\right)$ and uniaxial compressive $\left(R_{c}\right)$ strengths at the fracture point for the starting and doped ( +5 and $+10 \%$ of graphite powder) bentonitic grouts as a function of the load applied to the sample $\left(F_{f}\right.$ and $\left.F_{c}\right)$. Symbols are as follows: diamonds for the starting grout; squares for the grout $+5 \%$ of graphite powder; triangles for the grout $+10 \%$ of graphite powder. Open symbols are for tests at 14 days, filled symbols for those at 28 days

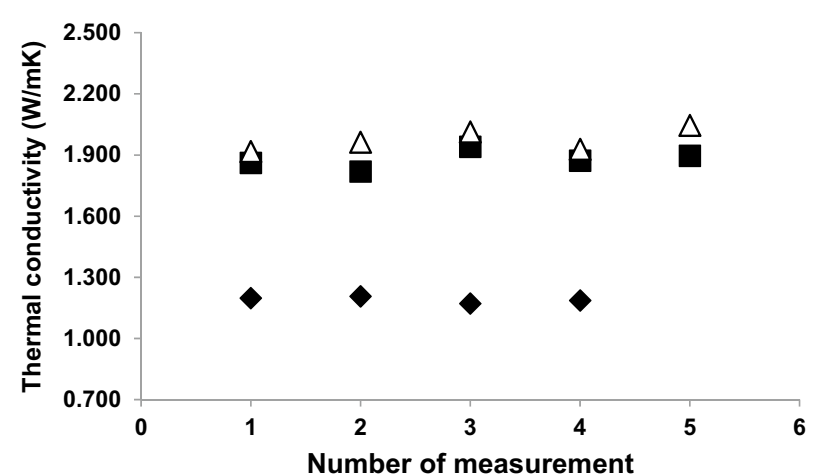

Fig. 2 Diagram of the repeated measurements of thermal conductivity obtained on the starting and doped ( +5 and $+10 \%$ of graphite powder) bentonitic grouts. Symbols are as follows: diamonds for the starting grout; squares for the grout $+5 \%$ of graphite powder; triangles for the grout $+10 \%$ of graphite powder

and its total length (function of linear meters of perforation). Abatement of costs are, therefore, due to considerable reduction of the amount of bentonitic grout used to seal the borehole, in a way that: (1) fixing the borehole depth, the probe cross-section can be reduced (common probes diameters are 20, 25, 32 and $40 \mathrm{~mm}$ ); (2) fixing the probe cross-section, the final depth of perforation can be shortened. In the former instance, 
savings principally come from lower costs of perforation, geothermal probes and their related cables/hoses, whereas in the latter chiefly from reduction of linear meters of the boreholes.

\section{Effects on the total borehole length reduction}

Calculations of the borehole length reduction can be performed through the general equations for sizing of thermal exchangers in the ground accepted by the ASHRAE (American Society of Heating, Refrigerating and Air-Conditioning Engineers), which were developed by Ingersoll et al. (1954) and later implemented by Kavanaugh and Rafferty (1997). Length of the borehole needed for heating $\left(L_{\mathrm{h}}\right)$ and cooling $\left(L_{\mathrm{c}}\right)$ can be, respectively, obtained from the following equations:

$$
\begin{aligned}
& \left.L_{\mathrm{h}}=Q_{\mathrm{a}} \cdot R_{\mathrm{ga}}+Q_{\mathrm{g}, \mathrm{hD}} \cdot\left[R_{\mathrm{b}}+\left(\mathrm{PLF}_{\mathrm{m}, \mathrm{hD}} \cdot R_{\mathrm{gm}}\right)+\left(R_{\mathrm{gd}} \cdot F_{\mathrm{sc}}\right)\right] / t_{\mathrm{g}}-\left[\left(t_{\mathrm{wi}}+t_{\mathrm{wo}}\right) / 2\right)\right]_{\mathrm{hD}}-t_{\mathrm{p}} \\
& \left.L_{\mathrm{c}}=Q_{\mathrm{a}} \cdot R_{\mathrm{ga}}+Q_{\mathrm{g}, \mathrm{cD}} \cdot\left[R_{\mathrm{b}}+\left(\mathrm{PLF}_{\mathrm{m}, \mathrm{cD}} \cdot R_{\mathrm{gm}}\right)+\left(R_{\mathrm{gd}} \cdot F_{\mathrm{sc}}\right)\right] / t_{\mathrm{g}}-\left[\left(t_{\mathrm{wi}}+t_{\mathrm{wo}}\right) / 2\right)\right]_{\mathrm{cD}}-t_{\mathrm{p}},
\end{aligned}
$$

where: $Q_{\mathrm{a}}$ is the average heat flux exchanged during 1 year (expressed in $\mathrm{W}$ ); $R_{\mathrm{ga}}$ is the equivalent thermal resistance per length unit of the ground (annual pulse, expressed in $\mathrm{m} \mathrm{K} / \mathrm{W}) ; Q_{\mathrm{g}, \mathrm{hD}}$ and $Q_{\mathrm{g}, \mathrm{cD}}$ are the project heat output at the ground side during the heating and cooling seasons, respectively (expressed in $\mathrm{W}$ ); $R_{\mathrm{b}}$ is the equivalent thermal resistance per length unit of the heat exchanger, corresponding to the thermal exchange between the heat transfer fluid and the borehole surface (expressed in $\mathrm{m} \mathrm{K} / \mathrm{W}$ ); $\mathrm{PLF}_{\mathrm{m}, \mathrm{hD}}$ and $\mathrm{PLF}_{\mathrm{m}, \mathrm{cD}}$ are the monthly part load factors during the heating and cooling seasons, respectively; $R_{\mathrm{gm}}$ is the equivalent thermal resistance per length unit of the ground (monthly pulse expressed in $\mathrm{m} \mathrm{K} / \mathrm{W}$ ); $R_{\mathrm{gd}}$ is the equivalent thermal resistance per length unit of the ground (daily pulse expressed in $\mathrm{m} \mathrm{K} / \mathrm{W}$ ); $F_{\mathrm{sc}}$ is the loss factor due to possible thermal short-circuits in the exchanger between input/output pipes; $t_{\mathrm{g}}$ is the ground temperature (in ${ }^{\circ} \mathrm{C}$ ) not disturbed by the exchanger; $t_{\mathrm{wi}}$ and $t_{\mathrm{wo}}$ are the input and output temperatures (in ${ }^{\circ} \mathrm{C}$ ) of the transfer fluid during the heating and cooling seasons; $t_{\mathrm{p}}$ is the penalty temperature (in ${ }^{\circ} \mathrm{C}$ ), which evaluates the interference between exchangers.

Results presented in this work put into evidence the effect of changing the parameter $R_{\mathrm{b}}$ in the two Eqs. (5) and (6) considering that:

$$
R_{\mathrm{b}}=R_{\mathrm{pp}}+R_{\mathrm{gr}}
$$

where $R_{\mathrm{pp}}$ is the total thermal resistance of pipes containing the heat transfer fluid and $R_{\mathrm{gr}}$ is the thermal resistance of the sealing grout (i.e., pipe/ground interface), both expressed in $\mathrm{m} \mathrm{K/W}$. The thermal resistance of the sealing grout $\left(R_{\mathrm{gr}}\right)$ can be calculated through the relation provided by Remund (1999), which is valid for a single input/output circuit as follows:

$$
R_{\mathrm{gr}}=1 / S_{\mathrm{b}} \cdot \lambda_{\mathrm{gr}}
$$

where $S_{\mathrm{b}}$ is the short-circuit factor and $\lambda_{\mathrm{gr}}$ is the thermal conductivity of the sealing grout. The short-circuit factor $\left(S_{\mathrm{b}}\right)$ can be calculated as follows: 


$$
S_{\mathrm{b}}=b_{0} \cdot\left(d_{\mathrm{b}} / D_{\mathrm{po}}\right)^{\beta 1} \text {, }
$$

where $\beta_{0}$ and $\beta_{1}$ are coefficients depending on the geometry of input/output pipes into the borehole (cf. Remund 1999 for the list of values), whereas $d_{b}$ is the borehole diameter and $D_{\mathrm{po}}$ that of the pipe (i.e., the probe diameter). Sensitivity in changing $\lambda_{\mathrm{gr}}$ on the total sizing of the low-enthalpy geothermal installation (here evaluated in terms of borehole length) can be, therefore, calculated combing the relations (8) and (9). Indeed, the total thermal exchange between the heat transfer fluid and the borehole surface (i.e., the equivalent thermal resistance $R_{\mathrm{b}}$ ) is strictly dependent on the thermal conductivity of the sealing material that operates at the probe/ground interface.

Fixing the technical configuration of the thermal exchange system (i.e., geometry of the input/output probe pipes, borehole and probe diameters), changes of $\lambda_{\mathrm{gr}}$ from $1.191 \mathrm{~W} / \mathrm{m} \mathrm{K}$ (average of the pure starting grout material) up to $1.878 \mathrm{~W} / \mathrm{m} \mathrm{K}$ (average of the grout material doped with $5 \%$ of graphite powder) are able to reduce the final $R_{\mathrm{gr}}$ from 0.12 down to $0.07 \mathrm{~m} \mathrm{~K} / \mathrm{W}$. Although small, these variations have important effects on the final calculation of the total borehole length either in heating or cooling conditions ( $L_{\mathrm{h}}$ and $L_{\mathrm{c}}$ in Eqs. 5 and 6, respectively) due to changes of the $R_{\mathrm{b}}$ value. A simple calculation can be obtained by fixing all the environmental parameters and the related energetic budgets. As a mere example, decreasing of the equivalent thermal resistance $R_{\mathrm{b}}$ applied to a small edifice (surface $\sim 150 \mathrm{~m}^{2}$, for which $\sim 200$ linear meters of borehole are needed) can entail a total borehole length reduction on the order of 30-40 m (ca. $15-20 \%)$. Of course, the larger is the sizing of the low-enthalpy geothermal installation the higher is the economic benefit due to reduction of the total borehole length.

\section{Conclusions}

In this study, two bentonitic grouts doped with 5 and $10 \%$ of pure graphite powder have been considered for what concerns their flexural and uniaxial compressive strengths, together with thermal conductivity. Experimental results have put into evidence good perspectives for their possible use in low-enthalpy geothermal applications, especially as sealing material of probes into boreholes. Both the experimental bentonitic mixtures display improved mechanical and physical properties, although the cost/benefit ratio appears more favorable for starting materials doped with low percentages (5\%) of graphite powder as additive. Importance of such experimental studies consists in finding new materials that, through implementation of the thermal exchange between the technological system and the subsoil, are able to make low-enthalpy geothermal installations even more competitive in the renewable energy market.

\section{Authors' contributions}

MV conceived the work, performed the mechanical and physical tests, elaborated the data and packed the whole paper The author read and approved the final manuscript.

\section{Author details}

${ }^{1}$ Dipartimento di Scienze Biologiche Geologiche e Ambientali - Sezione di Scienze della Terra, Università degli Studi di Catania, Corso Italia 57, 95129 Catania, Italy. ${ }^{2}$ Istituto Nazionale di Geofisica e Vulcanologia - Sezione di Catania, Osservatorio Etneo, Piazza Roma 2, 95125 Catania, Italy.

\section{Acknowledgements}

MV is pleased to thank Dr. Giuseppe Belfiore at EarTherm for his technical support and availability of materials. Dr.

Giuseppe Cristaldi at Sidercem is greatly acknowledged for the preparation of bentonitic grout mixtures and his supervision during mechanical tests. MV is also grateful for the availability of the Technical Physics Lab at DIEEl of the University of Catania. Three anonymous reviewers are greatly acknowledged for their helpful suggestions, which have finally led to improvement of the paper. 


\section{Competing interests}

Not applicable.

Availability of data and materials

All data and materials considered in this work can be requested to the author at the e-mail address: m.viccaro@unict.it.

\section{Ethics approval and consent to participate}

Not applicable.

Funding

This work has been supported by research funds granted to Marco Viccaro by the University of Catania (FIR 2014 cod.

2F119B and PRA 2016-18 cod. 22722132120) and by EarTherm (Spin-Off Enterprise of the University of Catania).

\section{Publisher's Note}

Springer Nature remains neutral with regard to jurisdictional claims in published maps and institutional affiliations.

\section{Received: 24 November 2017 Accepted: 1 March 2018}

Published online: 05 March 2018

\section{References}

Alrtimi AA, Rouainia M, Manning DAC. Thermal enhancement of PFA-based grout for geothermal heat exchangers. Appl Therm Eng. 2009;54(2):559-64.

Anbergen H, Frank J, Muller L, Sass I. Freeze-thaw cycles on borehole heat exchanger grouts: impact on the hydraulic properties. Geotech Test J. 2014;37:639-51.

Banks D. An introduction to thermogeology: ground source heating and cooling. Hoboken: Wiley-Blackwell; 2012. p. 526

Blazquez CS, Martin AF, Nieto IM, Garcia PC, Sanchez Perez LS, Gonzalez-Aguilera D. Analysis and study of different grouting materials in vertical geothermal closed-loop systems. Renew Energy. 2017;114:1189-200.

Borinaga-Treviño R, Pascual-Muñoz P, Castro-Fresno D, Del Coz-Diaz JJ. Study of different grouting materials used in vertical geothermal closed-loop heat exchangers. Appl Therm Eng. 2013;50(1):159-67.

Clauser C, Huenges E. Thermal conductivity of rocks and minerals. In: Ahrens TJ, editor. Rock physics and phase relations - a handbook of physical constants, vol. 3. Washington, D.C: AGU Reference Shelf; 1995. p. 105-26.

Delaleux F, Py X, Olives R, Dominguez A. Enhancement of geothermal borehole heat exchangers performances by improvement of bentonite grouts conductivity. Appl Therm Eng. 2012;33-34(1):92-9.

Desmedt J, Van Bael J, Hoes H, Robeyn N. Experimental performance of borehole heat exchangers and grouting materials for ground source heat pumps. Int J Energy Res. 2012;36(13):1238-46.

DIN 18136:2003-2011. Soil—investigation and testing — Unconfined compression test. 2003-2011.

Eppelbaum L, Kutasov I, Pilchin A. Applied geothermics. Berlin: Springer-Verlag; 2014. p. 751.

Erol S, Francois B. Efficiency of various grouting materials for borehole heat exchangers. Appl Therm Eng. 2014;70(1):788-99.

Erol S, Francois B. Freeze damage of grouting materials for borehole exchangers: experimental and analytical evaluations Geomech Energy Environ. 2015;5:29-41.

Fleuchaus P, Blum P. Damage event analysis of ground source heat pump systems in Germany. Geothermal Energy. 2017;5:10. https://doi.org/10.1186/s40517-017-0067-y.

Florides G, Kalogirou S. Ground heat exchangers—a review of systems, models and applications. Renew Energy. 2007;32(15):2461-78.

Fukai J, Kanou M, Kodama Y, Miyatake O. Thermal conductivity enhancement of energy storage media using carbon fibers. Energy Convers Manag. 2000;41:1543-56.

Indacoechea-Vega I, Pascual-Muñoz P, Castro-Fresno D, Calzada-Perez MA. Experimental characterization and performance evaluation of geothermal grouting materials subjected to heating-cooling cycles. Constr Build Mater. 2015;98:583-92.

Ingersoll LR, Zobel OJ, Ingersoll AC. Heat conduction: with engineering and geological applications. New York: McGrawHill Book Co; 1954

Jobmann M, Buntebarth G. Influence of graphite and quartz addition on the thermo-physical properties of bentonite for sealing heat-generating radioactive waste. Appl Clay Sci. 2009;44(3-4):206-10.

Kalaiselvam S, Parameshwaran R. Thermal energy storage technologies for sustainability_-systems design, assessment and applications. Elsevier: Academic Press; 2014. p. 430.

Karaipekli A, Sari A, Kaygusuz K. Thermal conductivity improvement of stearic acid using expanded graphite and carbon fiber for energy storage applications. Renew Energy. 2007;32:2201-10.

Kavanaugh SP, Rafferty K. Ground source heat pumps-design of geothermal systems for commercial and institutional buildings. ASHRAE Application Handbook. USA: American Society of Heating, Refrigerating and Air-Conditioning Engineers (ASHRAE); 1997.

Kim D, Kim G, Baek H. Relationship between thermal conductivity and soil-water characteristic curve of pure bentonitebased grout. Int J Heat Mass Transf. 2015;84:1049-55.

Kim D, Kim G, Park S, Baek H. Changes in the thermal conductivity of bentonite-based grouts with varying volumetric water content. Geosyst Eng. 2013;16(4):257-64.

Lee C, Lee K, Choi H, Choi HP. Characteristics of thermally-enhanced bentonite grouts for geothermal heat exchanger in South Korea. Sci China Ser E Technol Sci. 2010;53:123-8.

Lee C, Park M, Nguyen TB, Sohn B, Choi JM, Choi H. Performance evaluation of closed-loop vertical ground heat exchangers by conducting in situ thermal response tests. Renew Energy. 2012;42:77-83. 
Remund CP. Borehole thermal resistance: laboratory and field studies. ASHRAE Trans. 1999;105:1.

Sari A. Thermal energy storage characteristics of bentonite-based composite PCMs with enhanced thermal conductivity as novel thermal storage building materials. Energy Convers Manag. 2016;117:132-41.

Smith MD, Perry RL. Borehole grouting: field studies and thermal performance testing. ASHRAE Transactions, Proceedings of the 1999 ASHRAE Winter Meeting. 1999, vol. 105, code 55431

Tang AM, Cui YJ, Le TT. A study on the thermal conductivity of compacted bentonites. Appl Clay Sci. 2008:41:181-9.

UNI EN 12664. Thermal performance of building materials and products. Determination of thermal resistance by means of guarded hot plate and heat flow meter methods. Dry and moist products of medium and low thermal resistance. 2002.

UNI 11152. Aqueous suspensions for injections of hydraulic binders—characteristics and test methods (in Italian). 2005. UNI EN 445. Grout for prestressing tendons-test methods. 2007.

UNI EN 196-1. Methods for test of cements—Part 1: determination of mechanical strengths. 2016.

Wang H, Lu J, Qi C. Thermal conductivity of sand-bentonite mixtures as a backfill material of geothermal boreholes. Trans Geotherm Res Counc. 2011;35(2):1135-8.

\section{Submit your manuscript to a SpringerOpen ${ }^{\circ}$} journal and benefit from:

- Convenient online submission

- Rigorous peer review

- Open access: articles freely available online

- High visibility within the field

Retaining the copyright to your article

Submit your next manuscript at $\boldsymbol{\Delta}$ springeropen.com 